\title{
LA RETIRADA DEL REINO UNIDO DE LA UNIÓN EUROPEA
}

\author{
Araceli Mangas MarTín * \\ Real Academia de Ciencias Morales y Políticas \\ Departamento de Derecho Internacional Privado \\ y Derecho Internacional Público \\ Facultad de Derecho \\ Universidad Complutense de Madrid \\ amangas@der.ucm.es
}

\begin{abstract}
RESUMEN
Se analizan en este ensayo las consecuencias constitucionales, politicas y jurídicas derivadas de la salida del Reino Unido de la Unión Europea, incidiendo en las cuestiones más relevantes donde el impacto de tal decisión es mayor.

Palabras clave: Unión Europea, Reino Unido, política, Brexit, consecuencias.
\end{abstract}

\section{ABSTRACT}

In this essay we will study the constitutional, political and legal consequences derived from the United Kingdom's withdrawal from the European Union, emphasizing the most important issues where such a decision has a bigger impact.

Keywords: European Union, United Kingdom, Policy, Brexit, effects.

\section{ZUSAMMENFASSUNG}

In diesem Essay werden die verfassungsrechtlichen, politischen und juristischen Konsequenzen des Ausstiegs des Vereinigten Königreichs aus der Europäischen Union untersucht, wobei die jeweils relevantesten Fragen berücksichtigt werden, deren Auswirkungen am gravierendsten sind.

Schlüsselwörter: Europäische Union, Vereinigtes Königreich, Politik, Brexit, Konsequenzen.

* Catedrática de Derecho Internacional Público y Relaciones Internacionales de la Facultad de Derecho de la Universidad Complutense de Madrid y Académica de Número de la Real Academia de Ciencias Morales y Políticas de España. 
SUMARIO: I. INTRODUCCIÓN.-II. UNA PROMESA LANZADA EN CAMPAÑA ELECTORAL.-III. ¿QUÉ PRETENDÍA Y QUÉ LOGRÓ EL REINO UNIDO?-1. Gobernanza económica de la eurozona y salvaguardias para no participantes.-2. Competitividad.-3. La cuestión de la «Unión cada vez más estrecha».-4. El control de la subsidiariedad por los Parlamentos nacionales.-5. La libre circulación de ciudadanos de la UE.-IV. VALORACIÓN GENERAL DEL ACUERDO. POSICIÓN DE LOS ESTADOS MIEMBROS.-V. NATURALEZA JURÍDICA DE LA DECISIÓN DE LOS ESTADOS MIEMBROS.VI. EL REFERÉNDUM Y EL DERECHO DE RETIRADA.-VII. EL TRIUNFO DE LA RETIRADA. CONSECUENCIAS.-1. La falta de alternativas a la membresía europea.-2. Algunos problemas intracomunitarios. Gibraltar.VIII. RETIRADA Y RELACIONES EXTERIORES.-1. No hay restitutio in integrum.-2. Reconstruir su propia red de acuerdos con terceros.-3. Impacto sobre la política exterior y de seguridad común.-4. La relación con Estados Unidos.IX. SEGURIDAD Y DEFENSA.-X. LUCHA CONTRA EL TERRORISMO.XI. CONCLUSIONES FINALES.

\section{INTRODUCCIÓN}

El referéndum sobre la permanencia del Reino Unido en la Unión Europea (en adelante UE) ha tenido como resultado que el país saldrá de la Unión, aunque con un porcentaje de votos muy ajustado: el 51,9 por 100 de los votantes a favor y el 48,1 por 100 en contra.

La relación entre la UE y el Reino Unido ha sido siempre bastante tormentosa. Sin duda ha sido un tema recurrente en los medios de comunicación, en particular en la prensa británica, desde antes de su ingreso en 1973.

Los conservadores, con Edward Heath al frente del gobierno británico, negociaron y firmaron el Tratado de Adhesión de 1972, y los laboristas accedieron al gobierno con la promesa de un referéndum sobre la retirada. Entonces, como ahora, era la forma de un chantaje: renegociaron la adhesión, consiguieron ciertas mejoras (relacionadas con la participación británica en el presupuesto y con los productos lácteos procedentes de Nueva Zelanda) y con las nuevas y más favorables condiciones se convocó el referéndum en 1975, haciendo campaña el propio gobierno laborista (salvo un par de ministros) a favor de la permanencia del Reino Unido en las entonces denominadas Comunidades Europeas y los británicos se decantaron por el «sí». En 1979 ganó las elecciones el Partido Conservador, liderado por Margaret Thatcher, quien consideró insuficientes los términos de la renegociación, consiguiendo nuevas mejoras en materia financiera (el eterno cheque británico), agrícola y pesquera. 
Volvieron a crear problemas en 1992 durante la negociación del Tratado de Maastricht: lograron eliminar los términos «federal» (para el carácter de la Unión) y «legislativo» para los actos normativos de la UE, y quedaron fuera del Protocolo Social (aceptado años más tarde por Tony Blair) y de la tercera fase de la Unión Monetaria, es decir, del euro como moneda única (opt out).

En la reforma operada por el Tratado de Ámsterdam lograron zafarse de la plena libre circulación de personas — cuando se comunitarizó el Convenio de Schengen normalizando sus cláusulas en el texto del antiguo Tratado CE y Derecho derivado-y, por tanto, de las normas de asilo.

De nuevo en el siglo XXI, las reformas que introdujo el Tratado de Lisboa, firmado el 13 de diciembre de 2007, a los dos grandes tratados en vigor (Tratado de la UE y Tratado de Funcionamiento de la UE —en adelante TUE y TFUE-) fueron aceptadas por el gobierno laborista de Gordon Brown y ratificadas por el Parlamento británico, si bien ya con algunas cláusulas especiales que bloqueaban la interpretación de la Carta de los Derechos Fundamentales en el Reino Unido. A pesar de la flexibilidad, el premier Cameron ha exigido renegociarlo recuperando competencias «de Bruselas».

Más desencuentros. En 2012 el gobierno de coalición conservadorliberal optó por no ser parte del Tratado de Estabilidad, Coordinación y Gobernanza de 2 de marzo de 2012. Hay que recordar que el Acuerdo de Coalición de mayo de 2010 entre conservadores y liberales establecía que el gobierno aseguraría que no hubiera más transferencia de soberanía a lo largo de la próxima legislatura, por lo que se negaron a ser parte del Tratado de Estabilidad, Coordinación y Gobernanza.

El Reino Unido se incorporó tarde y de mala gana al proyecto europeo, que no le entusiasmaba, pero que le era necesario al ir desmontando su imperio. También el proceso de integración necesitaba de un gran Estado, estable, influyente y con un gran ejército, en fin, una gran potencia. Por ser un Estado poderoso y necesario para la UE, casi imprescindible, ha tratado de lograr siempre condiciones especiales y privilegiadas, intentando forzar a los demás Estados miembros europeos a revisar los Tratados según los gustos e intereses británicos. Esto ha dado lugar a problemas singulares y se le ha percibido a veces como un caballo de Troya.

¿Por qué otro referéndum? Hay varios factores que explican esta vuelta a la carga de la reevaluación británica de su relación con la UE: la crisis económica y financiera general — aun siendo una economía saneada-, y el aumento en el apoyo popular a los partidos antieuropeos. En realidad, 
también ellos se han sentido cada vez más recelosos e incómodos según el proceso europeo avanzaba.

\section{UNA PROMESA LANZADA EN CAMPAÑA ELECTORAL}

Deseoso de lograr la mayoría absoluta excitando las emociones de su pueblo y un liderazgo sin fisuras del partido conservador, un discurso de Cameron en enero de 2013 presentó el referéndum de retirada como propuesta central de su campaña electoral, en la que obtuvo la mayoría absoluta en 2014. Igual que los laboristas en 1974.

Que no fue una idea meditada ni medida, sino buscando beneficio electoral, es constatable. El premier Cameron no consultó el calendario propio, ni el de sus socios, ni pensaron de qué forma podría lograr sus exigencias. El periodo de tiempo que estableció — «un referéndum antes de que finalice 2017»- hacía imposible una reforma formal de los Tratados antes de 2017. Ni Alemania, ni Francia, ni otros socios, querían una reforma de los Tratados antes de 2019. Además, el Reino Unido ejercería la Presidencia de turno de la UE en el segundo semestre de 2017; sería políticamente torpe y complicado si entonces se hubieran requerido nuevas negociaciones. Por otra parte, Alemania y Francia no quieren interferencias en sus procesos electorales de 2017, con opiniones públicas muy contrapuestas a la británica. Por su imprevisión, sólo le quedaba a Cameron adelantar el referéndum de la UE a junio del 2016 accediendo a una negociación por la vía rápida y política del acuerdo. Sólo lo que se pudiera convenir mediante acuerdos políticos y, eventualmente, reformas de Derecho derivado sería negociable, por lo que ha debido renunciar al acuerdo «formal, obligatorio e irreversible» que exigía la carta del premier Cameron ${ }^{1}$.

\section{III. ¿QUÉ PRETENDÍA Y QUÉ LOGRÓ EL REINO UNIDO?}

Podría resumirse en un concepto: flexibilidad para los compromisos y obligaciones adquiridos por el Reino Unido. Recuperar soberanía, libertad económica y de comercio. No tener compromisos. Sus exigencias se concretaron, después de muchas imprecisiones y exageraciones, en la citada

\footnotetext{
${ }^{1}$ Carta de 10 de noviembre de 2015 en https://www.gov.uk/government/uploads/ system/uploads/attachment_data/file/475679/Donald_Tusk_letter.pdf.
} 
carta formal al Consejo Europeo en la que abandonó algunas exigencias. Los británicos se pronunciarían en el referéndum, al decantarse por la retirada o la permanencia, sobre las reformas logradas por el Reino Unido en el funcionamiento de la Unión.

\section{Gobernanza económica de la eurozona y salvaguardias para no participantes}

El premier Cameron partía de una constatación objetiva de la que se hacía eco la Decisión del Consejo Europeo ${ }^{2}$ dando una solución al problema británico: en 2015-2016 los Estados miembros cuya moneda es el euro son diecinueve y otros nueve están fuera de la tercera fase, si bien reconocía que entre estos hay diferentes estatutos y el propio del Reino Unido tiene un opt out; no tiene obligación de pasar a la tercera fase. El Reino Unido no se oponía a que los Estados del euro quisieran asegurar la estabilidad de su moneda, pero entendía que muchas reformas en materia fiscal, bancaria, de seguros, etc., no deberían afectar al mercado interior ni a los intereses de los Estados que no están en el euro. En estos años de crisis los miembros de la eurozona han abordado reformas de gran profundidad política y económica (convergencia económica, fiscal y social; estabilidad financiera e inversión, y refuerzo de la gobernanza y del marco institucional de la eurozona) eludiendo de forma sinuosa, a través de mayorías cualificadas de Derecho derivado, reformas de los Tratados que requieren unanimidad.

Las pretensiones del Reino Unido en esta materia no eran exageradas o sin fundamento alguno. Ciertamente, todos los Estados miembros están vinculados por la primera y segunda fase de la Unión Económica y Monetaria, sin excepción alguna. Lo que no les afecta son las obligaciones de la tercera fase relativas a la moneda única y su protección. Es razonable pensar que la construcción de la convergencia económico-fiscal debe disponer de «cortafuegos», cuando sea posible, y evitar legislar sobre los Estados que tienen una excepción legal al euro. El equilibrio basado en el respeto mutuo hace posible el entendimiento y beneficios al lograr que no hubiera interferencias o frenos ni expansión no querida.

\footnotetext{
${ }^{2}$ Decisión de los jefes de Estado o de gobierno, reunidos en el seno del Consejo Europeo, relativa a un nuevo régimen del Reino Unido en la UE de 19 de febrero de 2016, Anexo I, «Un nuevo régimen del Reino Unido en la UE» (DO, L 69/I, de 23 de febrero de 2016).
} 
Además, ello facilitaría a los Estados del euro poder decidir una mayor profundización de la Unión Económica y Monetaria sin pensar en las cortapisas o consecuencias para los ajenos a la eurozona y salvaguardando los derechos y competencias de los no participantes. A cambio del principio de no interferencia en el estatuto de los no participantes, la UE y sus Estados del euro se verían compensados con el compromiso de que aquéllos no crearían obstáculos a la intensificación de la Unión Económica y Monetaria y la facilitarían.

No se puede ocultar que tras la preocupación británica por el impacto de la Unión Económica y Monetaria había un claro interés del Reino Unido en proteger su libertad de legislar para conseguir la preservación de la preeminencia de la City financiera de Londres.

Se proyectó un procedimiento de «freno de emergencia» de toma de decisiones, si bien hubiera requerido modificar una Decisión del Consejo; bastaría que «un solo» Estado no participante en la Unión Bancaria mostrara su oposición motivada a que el Consejo adoptase un acto por mayoría cualificada para que el Consejo debatiera la cuestión ${ }^{3}$. El Estado justificaría su oposición indicando la forma en que el proyecto de acto podría interferir en los Estados ajenos al euro 4 . Hubiera sido una concesión importante al Reino Unido a pesar de que la eurozona estimaba que debía ser una acción colectiva (por ejemplo, de tres Estados). Se intentó por la eurozona hasta las horas finales que fuese una acción colectiva, pero el Reino Unido no cedió en su exigencia.

\section{Competitividad}

Nadie podía negarse a la lógica de una integración ampliada a otros sectores y, por tanto, la expansión del mercado interior a servicios, energía, industria digital, etc. $\mathrm{O}$ a la aceleración de acuerdos con Estados Uni-

3 Anexo II, Proyecto de Decisión del Consejo sobre las disposiciones específicas relacionadas con la gestión eficaz de la unión bancaria y las consecuencias de la mayor integración de la zona del euro (DO, L 69/I, de 23 de febrero de 2016). Se hubiera modificado la Decisión 2009/857/CE, de 13 de diciembre de 2007.

${ }^{4}$ Este mecanismo de suspensión de la toma de decisiones en manos de un solo Estado para abrir un periodo de debate centrado en las consecuencias de una norma común recuerda mucho el mecanismo del «compromiso de Ioannina» de 1995 (a iniciativa española frente a las consecuencias de la ampliación a Austria, Finlandia y Suecia) y retomado por el Tratado de Funcionamiento en la reforma de Lisboa para la formación de la mayoría, pero se requerían varios Estados (tres) y un porcentaje de población. 
dos, Japón y la India, siempre que reúnan elementos equilibrados de reciprocidad, beneficio mutuo y adecuadas salvaguardias.

El Reino Unido siempre tuvo especial sensibilidad frente a lo que ha denominado «las trabas burocráticas de Bruselas». Estas repetidas críticas tienen sólo algo de verdad. Al margen del tópico, pedir contención en la regulación es beneficioso para el crecimiento, la competitividad y el empleo. Una cosa es contención y equilibrio, y otra hacer emerger un liberalismo económico a ultranza, privando de todo control y normas sobre el mercado. Esta exigencia en su punto de equilibrio no hubiera requerido revisar los Tratados. Exigía un cambio de actitud y, a lo sumo, modificar normas de Derecho derivado que pudieran suponer rémora o carga burocrática para las empresas sin la compensación de beneficios o garantías necesarias para todos: empresarios, poderes públicos y consumidores.

La respuesta del Consejo Europeo a la preocupación británica de fondo fue «un compromiso decidido de simplificación normativa y reducción de la carga administrativa, inclusive, cuando proceda, por medio de la retirada o derogación de actos legislativos, y una mejor utilización de las evaluaciones de impacto y de las evaluaciones ex post a lo largo de todo el ciclo legislativo, tanto a escala de la UE como nacional» ${ }^{5}$.

En definitiva, la Comisión Europea hubiera debido simplificar la legislación, evitar el exceso normativo y reducir la carga administrativa para las empresas $^{6}$. Esto deberá hacerse, al margen del resultado negativo del referéndum. Será positivo para todos, sí. Pero chasta dónde debe llegar la inhibición legislativa, la no exhaustividad y la acción derogatoria? El Consejo Europeo ha puesto unos límites: una elevada protección de los consumidores, trabajadores, salud y medio ambiente. Es una pretensión que no va a dejar indiferente al Parlamento Europeo.

\section{La cuestión de «una unión cada vez más estrecha»}

Era la cuestión más delicada en términos políticos y jurídicos. Es bien sabido que el compromiso de una «unión cada vez más estrecha» apareció originalmente en el preámbulo del Tratado de Roma en 1957 (cuando el Reino Unido no era ni quiso ser miembro). En el Tratado CECA de 1951

5 Anexo III, Declaración del Consejo Europeo sobre la competitividad (DO, L 69/I).

${ }^{6}$ Anexo IV, Declaración de la Comisión Europea relativa a un mecanismo de aplicación de la subsidiariedad y un mecanismo de aplicación de la reducción de las cargas $(D O$, L 69/I, de 23 de febrero de 2016). 
no se utiliza, pero sí la idea de «más amplia y profunda». Desde la entrada en vigor de la reforma de Maastricht en 1993, este enunciado de la UE se recoge en el art. 1 del Tratado de la UE (entonces art. A) ${ }^{7}$. La clave es que está en el articulado, es una obligación legal. Aunque son lentos de reflejos, los británicos son buenos juristas.

Reconocía Cameron en su carta citada que, si bien «una unión cada vez más estrecha» puede seguir siendo un objetivo para otros países de la UE, el Reino Unido ya no quiere estar atado a la ambición de «más Europa». Quería romper esa inercia de más y más poderes que se transfieren desde los Estados miembros a las instituciones de la UE o, más exactamente, exige que su país no asuma la obligación «constitucional» de trabajar en el seno de la UE por la progresividad «como obligación legal, formal y camino irreversible».

La construcción europea es una idea dinámica que atañe a muchas generaciones. La UE es evolutiva, progresiva y se construye por sucesivas generaciones de europeos que van aportando nuevos elementos a la unidad europea. Con la retirada británica no habrá que expulsar ese precepto ni exonerar de la obligación de «actitud».

Esa expresión responde a una concepción filosófica y jurídica sobre la idea de proceso, de construcción intergeneracional, de evolución, de adaptación a los tiempos y necesidades. Y no supone ningún automatismo. Cualquier ampliación de competencias exige una reforma de los Tratados. Ese compromiso no es una mancha de aceite que expanda por sí la integración ni exija la integración de soberanías hasta su extinción y sin control parlamentario nacional.

$\mathrm{El}$ art. 1 seguirá siendo aplicable a todos, aunque sea más filosófico que jurídico, si bien ninguno está obligado a una «ulterior» integración política en el seno de la Unión Europea, pues cualquier cambio en los Tratados requiere unanimidad.

\section{El control de la subsidiariedad por los Parlamentos nacionales}

El premier británico también suscitaba desconfianza hacia la aplicación del principio de subsidiariedad. Su lema era «Europa donde sea necesaria,

${ }^{7}$ Precisamente, en diciembre de 1992 la presidencia holandesa del Consejo Europeo pasó esa frase («unión cada vez más estrecha») del preámbulo al articulado como compensación sustitutiva a la eliminación de la expresión «vocación federal» de la Unión que los británicos vetaron en el proyecto de Tratado de Maastricht en vísperas de su adopción. 
norma nacional cuando sea posible». No es descartable ni descabellada la idea. Se puede suscribir en apariencia. Pero bajo ese lema seductor lo que querían era: primero, repatriar competencias «de Bruselas», lo que no se impide por el Tratado y se prevé expresamente desde la reforma de Lisboa (art. 48.2 TUE), y segundo, y probablemente inaceptable, pretende que el Consejo pueda vetar y someter a la Comisión Europea, instrumentalizando a los Parlamentos nacionales. Hay que reconocer que el Reino Unido no es el único, ni estaba solo.

Muy distinto era el compromiso que hubieran adquirido los miembros del Consejo de tener que aceptar la suspensión del proyecto del acto legislativo de que se trate hasta que el proyecto se modificara por la Comisión para tener en cuenta los dictámenes motivados. Era un chantaje al margen de los Tratados y de gran impacto institucional.

Esta parte de la Decisión del Consejo Europeo introducía distorsiones jurídicas que hubieran podido afectar al principio constitucional del equilibrio institucional, tantas veces protegido por el Tribunal de Justicia de la UE cuando la Comisión es la autora del proyecto ${ }^{8}$. Era una presión excesiva de los gobiernos, de una sola de las cámaras legislativas de la UE (el Consejo y no el Parlamento), sobre la institución autora del proyecto legislativo e inaceptable legalmente si es sobre la Comisión.

\section{La libre circulación de ciudadanos de la UE}

La saneada economía del Reino Unido ha sido un polo de atracción para numerosos ciudadanos de la UE. El gobierno británico proponía restricciones a los beneficios y prestaciones gubernamentales como una forma de reducir los factores de atracción hacia el Reino Unido. Es cierto que el hecho de que un Estado miembro atraiga a un gran número de ciudadanos de la $\mathrm{UE}$ a su territorio puede plantear distorsiones y cargas excesivas.

Las prestaciones sociales no contributivas y, en general, la seguridad social es competencia de cada Estado miembro, no de la UE. El origen del atractivo está en la propia normativa británica de subsidios y, claro, en el principio de igualdad de los ciudadanos de la UE, si bien éste no es irrestricto. También se dan situaciones similares en otros Estados como Aus-

${ }^{8}$ Son clásicas las Sentencias del Tribunal de Justicia núm. 294/83, de 23 de abril de 1986, Los Verdes; núm. C-302/87, de 27 de noviembre de 1988, Parlamento Europeo c. Consejo (Comitología), y núm. C-70/88, de 22 de mayo de 1990, Parlamento c. Consejo (Chernobyl). 
tria, Bélgica, Países Bajos y Alemania, en los que se reconocen prestaciones o subsidios sociales no contributivos (por ejemplo, de vivienda, subsidio familiar por los hijos, de transporte, de espera del primer trabajo, espera en búsqueda de empleo, etc.). El Reino Unido no estaba solo, si bien las pretensiones británicas irritaban a los Estados del este y del sur.

El Tratado de Funcionamiento de la UE (TFUE) reconoce el derecho de los ciudadanos de la Unión a circular y a residir libremente en el territorio de los Estados miembros, si bien lo supedita a las «limitaciones y condiciones previstas en los Tratados y en las disposiciones adoptadas para su aplicación» (art. 21.1); también prohíbe toda discriminación por razón de la nacionalidad «en el ámbito de aplicación de los Tratados» (art. 18). El derecho de libre circulación y residencia no es, pues, un derecho irrestricto.

El derecho de libre circulación por periodos inferiores de tres meses es irrestricto para la ciudadanía de la UE, pero sin beneficios sociales?.

Ahora bien, residir por más de tres meses no es un derecho irrestricto. La Directiva 2004/38 es la «ley» europea que establece las condiciones de ejercicio previstas en el art. 21 TFUE y exige, o bien tener un trabajo, o bien tener recursos suficientes y un seguro médico para que ningún ciudadano sea una carga para el Estado de acogida (con unas adaptaciones a los inactivos, como, por ejemplo, los estudiantes). Es claro en la Directiva que el derecho a residir de los inactivos por periodos superiores a tres meses en un Estado miembro sólo se disfruta si se reúnen esos dos requisitos.

La interpretación jurisprudencial del Tribunal de Justicia de la UE y el Derecho derivado vigente fueron la solución ofrecida para calmar la exagerada posición británica y encontrar restricciones proporcionadas en el acceso a prestaciones sociales.

El Tribunal de Justicia ha declarado que un ciudadano de la Unión sólo puede reclamar la igualdad de trato respecto de los nacionales del Estado miembro de acogida en materia de prestaciones sociales «si su estancia en el territorio de dicho Estado cumple los requisitos» de la Directiva 2004/38 $8^{10}$ (medios económicos y seguro médico). El resto de estancias

${ }^{9}$ La residencia por un periodo de hasta tres meses limita las condiciones o las formalidades del derecho de residencia a la exigencia de estar en posesión de un documento de identidad o pasaporte válidos (art. 6 de la Directiva 2004/38).

${ }^{10}$ Sentencia del TJUE núm. C-333/13, de 11 de noviembre de 2014, Elisabeta Dano y Florin Dano, ap. 69. En este caso, relativo a una madre y su hija menor rumanas, la madre no trabajaba ni tenía recursos, viviendo junto a familiares en Alemania. También en Sentencia núm. C-46/12, de 21 de febrero de 2013, LN y Styrelsen for Videregående Uddannelser og Uddannelsesstøtte. 
son ilegales, aunque puedan ser toleradas, pero no dan derecho a beneficios no contributivos para los inactivos.

Por otro lado, el art. 24.2 de la Directiva 2004/38 dispone que «el Estado miembro de acogida no estará obligado a conceder el derecho a prestaciones de asistencia social, ni estará obligado, antes de la adquisición del derecho de residencia permanente, a conceder ayudas de manutención consistentes en becas o préstamos de estudios, incluidos los de formación profesional, a personas que no sean trabajadores por cuenta ajena o propia, personas que mantengan dicho estatuto o miembros de sus familias» (cursiva añadida). La residencia permanente se adquiere a los cinco años de residencia. Ese precepto supone una excepción al principio de no discriminación, confirmado en abundante jurisprudencia del TJUE.

Limitar las prestaciones especiales no contributivas establecidas por autoridades públicas, sea a escala nacional, regional o local, a las que recurre un ciudadano de la UE desplazado a otro Estado y que no dispone de recursos suficientes para sus necesidades básicas y las de los miembros de su familia, tiene su razón objetiva en la necesaria previsión presupuestaria para evitar que «tales personas puedan convertirse en una carga para las finanzas públicas del Estado miembro de acogida que pueda tener consecuencias para el nivel global de la ayuda que puede conceder dicho Estado». Para el Tribunal, la exigencia del art. 7.1.b) de la Directiva 2004/38 de disponer de recursos suficientes y seguro médico que cubra todos los riesgos «pretende impedir que los ciudadanos de la Unión que no ejerzan una actividad económica utilicen el sistema asistencial del Estado miembro de acogida para garantizar su subsistencia» ${ }^{11}$.

Y ha estimado «legítimo que un Estado miembro de acogida desee asegurarse de la existencia de un vínculo real entre el solicitante de una prestación y ese Estado miembro competente», pues la propia Directiva 2004/38 exige «evitar que los beneficiarios del derecho de residencia, incluidos los estudiantes, se conviertan en una carga excesiva para la asistencia social del Estado miembro de acogida durante un primer periodo de estancia» (de tres meses a cinco años). Por ello estima legal un régimen nacional que exige que «la existencia de un vínculo real con el Estado miembro de acogida podría responder, en principio, a un objetivo legítimo que pueda justificar restricciones de los derechos a circular y residir libremente en el territorio de los Estados miembros» ${ }^{12}$. Esta idea de condicio-

${ }^{11}$ Sentencia del TJUE, Dano, aps. 63 y 76.

${ }^{12}$ Sentencia del TJUE núm. C-75/11, de 4 de octubre de 2012, Comisión v. Austria. 
nar los beneficios sociales a la existencia de «vínculos reales» es acogida en la Decisión por el Consejo Europeo y éste recuerda, sin citar sentencias concretas, la jurisprudencia del Tribunal de Justicia.

No hubo concesiones especiales ni régimen especial en esta materia para los británicos. En consecuencia, el marco legal para las restricciones que planteó el Reino Unido estaba en la propia Directiva 2004/38 y en la interpretación equilibrada del TJUE: se pueden restringir las prestaciones sociales que concede un Estado miembro a sus nacionales (para desempleados, estudiantes, etc.) cuando el ciudadano de la UE que las reclama está en situación temporal de búsqueda de empleo durante los primeros cinco años de estancia (primer empleo o desempleado).

No es nuevo. Preocupaciones y soluciones restrictivas a un cierto abuso en la solicitud de ayudas sociales también han sido admitidas en litigios sucedidos en Alemania y ya se estaban aplicando en relación con ciudadanos de la UE que se desplazan a ese país a buscar empleo al tiempo que solicitan ayudas como desempleados de larga duración ${ }^{13}$.

Parece razonable que la UE sea suficientemente flexible para dar cabida a los diferentes sistemas de bienestar nacional al mismo tiempo que garantiza las cuatro libertades. No hay que reformar el derecho originario. Lo que importa es que las restricciones se basen en criterios objetivos y no sean desproporcionados respecto a los objetivos que persiguen. Por tanto, podrán restringirse los beneficios sociales a los solicitantes de empleo (de primer empleo o desempleados desplazados a buscar empleo) con el derecho ya en vigor. No con carácter general para los ciudadanos de la UE que obtenga un trabajo y entren en el ciclo productivo.

Un problema distinto es si un solicitante de empleo de la UE no ha encontrado trabajo en un plazo de seis meses; el Reino Unido pretendía su deportación. Ciertamente el Derecho de la UE sólo otorga un derecho de residencia por más de tres meses a los que están empleados por cuenta propia o bien tienen autosuficiencia económica y un seguro médico. De la jurisprudencia del Tribunal de Justicia se desprende que fuera de estos criterios se les puede negar la residencia por los Estados miembros, pero el TJUE afirma que mientras un ciudadano de la UE no solicite ayudas o beneficios y no sea carga para el Estado de acogida «no debería ser expulsado» (caso Dano), o mientras no incurra en los motivos de

13 Sentencia del TJUE núm. C-67/14, de 15 de noviembre de 2015, Jobcenter Berlin Neukölln v. Nazifa, Sonita, Valentina y Valentino Alimanovic. También las Sentencias núm. C-361/13, de 16 de noviembre de 2105, Comisión c. Eslovaquia, y núm. C-299-14, de 25 de febrero de 2016, García Nieto y Peñas Cuevas. 
expulsión de la Directiva 2004/38 (amenaza al orden público, la seguridad o la salud pública).

El Tribunal de Justicia ha afirmado que los Estados miembros están obligados a dar a los demandantes de empleo un plazo razonable para encontrar un trabajo, y que seis meses era razonable. Sin embargo, al mismo tiempo ha declarado que los ciudadanos de la UE no pueden ser expulsados siempre y cuando «se puedan presentar pruebas de que siguen buscando empleo y que tienen posibilidades reales de ser contratados», si bien se les puede denegar toda prestación social (caso Alimanovic). Fijar un plazo unilateralmente para obtener un trabajo puede originar un ilícito, y hacerlo mediante Derecho derivado no tiene base jurídica y exigiría la reforma del Tratado. Por ello, el Consejo Europeo no entra en ese charco y no responde al Reino Unido.

Es evidente que los problemas para el Reino Unido no acababan en el ciudadano de la UE demandante de empleo. Es bien sabido que el derecho de residencia se extiende a su familia (europea o de terceros Estados) y hay que tener en cuenta los abundantes fraudes con los matrimonios de conveniencia. Al menos el Derecho en vigor le ayudó y el Consejo Europeo recordaba que la Directiva 2004/38 permitía a los Estados miembros deportar y excluir a los ciudadanos de otros países de la UE por razones de orden público, seguridad y salud pública (con mayor razón a los extranjeros de terceros Estados) ${ }^{14}$.

La Decisión del Consejo Europeo en esta materia no se salió del guión del respeto del Derecho originario y derivado (con dos posibles modificaciones) y de su interpretación por el Tribunal de Justicia en los últimos años en una materia muy delicada socialmente. Se reconoció, siguiendo al pie de la letra al Tribunal de la UE, que «pueden imponerse condiciones en relación con determinadas prestaciones para velar por la existencia de un vínculo real y efectivo entre la persona afectada y el mercado laboral del Estado miembro de acogida». Aceptaba que es legal «la posibilidad de denegar las prestaciones sociales a personas que ejercen su libertad de circulación con el único objetivo de poder disfrutar de la ayuda social de otro Estado miembro cuando no disponen de recursos suficientes para optar al derecho de residencia». Y que los Estados estarían «capacitados para tomar medidas destinadas a prevenir el abuso de derecho o el fraude, como la presentación de

${ }^{14}$ La dificultad potencial para el Reino Unido en relación con la familia extranjera en este país es que pueden apelar la deportación en virtud de los derechos a la vida familiar garantizados por el Convenio Europeo de Derechos Humanos. Pero ése es otro problema, no asimilado aún por el Reino Unido, que la UE no le puede resolver. 
documentos falsificados, y para tratar casos de matrimonios de conveniencia contraídos o mantenidos con nacionales de terceros países con el fin de hacer uso de la libre circulación como vía para regularizar una estancia ilícita en un Estado miembro, o casos de uso de la libre circulación como vía para sortear las normas nacionales de inmigración aplicadas a nacionales de terceros países». El Reino Unido tuvo vía «libre» legal.

Además, el Consejo Europeo aceptó modificar el Reglamento 883/2004 (siempre que el referéndum hubiera sido positivo) en lo que respecta a la exportación de prestaciones por hijos que residen en un Estado miembro distinto de aquel en el que reside el trabajador (daba solución legal a las prestaciones por hijos del desplazado comunitario que permanecen en el país de origen). Los actuales trabajadores en el Reino Unido no perderían el derecho a la prestación y a exportarla, pero con una indexación diferida en el tiempo. El Consejo Europeo limitaba —si el referéndum hubiera sido positivo-, pues, la pretensión británica a las nuevas solicitudes de prestaciones por hijos que permanecen en el Estado de origen, de modo que la cantidad a percibir se adaptara al nivel de vida del Estado de residencia del niño.

Para actividades profesionales se preveía un mecanismo de alerta con restricciones en las prestaciones sociales no contributivas durante los primeros cuatro años de estancia y de forma gradual ante flujos de entrada de una magnitud excepcional bajo control europeo. Para ello se aceptaba modificar el Reglamento (CE) núm. 492/2011 relativo a la libre circulación de los trabajadores dentro de la Unión (siempre que el referéndum hubiera sido positivo). Cualquier Estado miembro hubiera podido notificar a la Comisión que se encuentra en una situación así y, a propuesta de la Comisión y con autorización del Consejo, se permitiría restringir el acceso a las prestaciones sociales vinculadas al ejercicio de una actividad profesional durante los primeros cuatro años de estancia y de forma gradual teniendo en cuenta el progreso de su vinculación real con el país de acogida. No era automático ni unilateral, sino bajo control institucional. Pero todo ha quedado pulverizado con la votación favorable a la retirada.

\section{VALORACIÓN GENERAL DEL ACUERDO. POSICIÓN DE LOS ESTADOS MIEMBROS E INSTITUCIONES}

Salvo la concesión relativa a que el Reino Unido no estaría ligado por la ambición de la progresividad de la Unión, hay que reconocer que el régi- 
men de trato otorgado no era exclusivo para ese Estado, sino que eran reformas para todos. La imagen en la prensa continental era que el Reino Unido había conseguido beneficios exclusivos o privilegiados.

Eran reformas que, si hubieran entrado en vigor, eran para todos, ciertamente logradas por la fuerza de la voluntad de un solo Estado al que otros muchos apoyaban en silencio. En efecto, lo preocupante de las exigencias británicas es que tuvieron la comprensión, cambiante según los temas, de otros gobiernos y de la propia Comisión. El Reino Unido contó con dos grandes aliados en su negociación: el presidente del Consejo Europeo, el polaco Donald Tusk, y el vicepresidente de la Comisión Europea, el neerlandés Frans Timmermans, y tras ellos sus gobiernos respectivos, que facilitaron una negociación discreta y exitosa de la Decisión de reforma en un tiempo récord; sin olvidar a otros Estados que comparten esas preocupaciones como Irlanda, Suecia y Dinamarca. Alemania sopló a favor de un acuerdo que facilitase a toda costa la permanencia del Reino Unido y no conllevase cambios en los Tratados en el corto plazo. Francia aceptaba flexibilidad sin exceso de liberalismo económico y siempre que se evitasen los cambios en los Tratados. Salvo lo relativo a la libre circulación, Polonia y Bulgaria apoyaban el resto de reivindicaciones británicas. España e Italia, en especial esta última, que fue más militante, apoyaban el libre comercio, pero no les gustaba rebajar sus expectativas de integración política; algunas propuestas interesaban especialmente a España, como la relativa al mercado de la energía y digital. Como un famoso equipo deportivo británico, el Reino Unido no ha caminado solo.

La canciller alemana, Angela Merkel, de cuyo europeísmo y compromiso yo no dudo, facilitó el entendimiento por su decidida voluntad de mantener a los británicos en la UE. Esta actitud de sentirse queridos gustó en el Reino Unido, aunque no ha sido suficiente dado el resultado del referéndum.

Sin embargo, el riesgo real, inmediato, de perder a la gran potencia que es el Reino Unido hubiera sido seguro si no se hacía alguna concesión. Y aun así el referéndum era incierto; una victoria del «no» daba alas a los populistas de toda laya en un momento en el que la democracia está en horas bajas en la Unión ${ }^{15}$.

15 A. Mangas Martín, «El abandono de los valores», Revista de la Asociación de exdiputados y exsenadores de las Cortes Generales, núm. 5 (2016), pp. 8-9. 


\section{NATURALEZA JURÍDICA DE LA DECISIÓN DE LOS ESTADOS MIEMBROS}

Aunque la Decisión del Consejo Europeo ya no podrá entrar en vigor planteaba serios problemas jurídicos sobre su legalidad. La solución a las inquietudes británicas tenía que ser el acuerdo articulado de los jefes de Estado o de gobierno, en su calidad de máximos representantes de los Estados miembros, aprovechando que estaban reunidos en el seno del Consejo Europeo. Como tal acuerdo internacional hubiera sido vinculante para los Estados miembros; sólo ellos podrían modificar o derogar su propio acuerdo normativo. Era un acuerdo netamente intergubernamental que obligaba a las partes a cumplirlo de buena fe.

No quisieron decidir como institución comunitaria, es decir, como Consejo Europeo, entre otros motivos porque no tenían competencia. No hay base jurídica en el Tratado ni en el TFUE para poder adoptar una Decisión así (art. 15 TUE) y no se corresponde con la Decisión tal como se define en el precepto sobre el sistema de actos de la UE (art. 288 TFUE). Ha habido varios precedentes, como la Declaración sobre Dinamarca en 1992 o sobre Irlanda en 2009 en las que se interpretaron diversos preceptos y las obligaciones asumidas por esos dos Estados, así como estatutos particulares en cuestiones concretas.

Al negar a la Decisión naturaleza de un acto de la UE, es decir, del Consejo Europeo como institución sujeta a control judicial del Tribunal de Justicia de la UE, quisieron evitar la posibilidad de su impugnación y eventual enjuiciamiento. No hubiera sido segura esa prevención, aunque en el fondo era un acto del Consejo Europeo mediante la ficción de constituirse en conferencia internacional y adoptar un acuerdo internacional en forma simplificada; incluso su disfraz, bajo el manto de conferencia internacional, no les hubiera librado de un posible recurso (por ejemplo, vía prejudicial).

Está el precedente de la Declaración de 30 de diciembre de 1961 de los jefes de Estado o de gobierno adoptada en la víspera del plazo dado por un precepto del antiguo Tratado de la Comunidad Europea para la entra$\mathrm{da}$ en vigor de la igualdad de remuneraciones entre mujeres y hombres. El Tribunal estimó que la voluntad de los Estados miembros «no ha podido modificar válidamente el plazo fijado por el Tratado» y la consideró de hecho como inexistente ${ }^{16}$.

${ }^{16}$ Sentencia núm. 43/75, de 8 de abril de 1976, Defrenne II, aps. 57-58. En el Dictamen 2/13 el Tribunal afirma que «los Estados miembros, debido a su pertenencia a la Unión, 
El Reino Unido notificó al secretario general de la ONU el acuerdo internacional. Si los Estados miembros entendían que esa Decisión era un acuerdo internacional en forma simplificada es aceptable esa calificación ${ }^{17}$, pero no les eximía de la obligación de respetar plenamente los Tratados, ni de la obligación de respetar sus normas constitucionales para comprometer al Estado con la necesaria autorización parlamentaria. Por ello, la vía elegida se aproximaba más al acuerdo político de los Estados miembros para eludir doblemente el procedimiento propio europeo de revisión de los Tratados y el procedimiento parlamentario nacional de autorización de acuerdos internacionales.

También hay que plantearse hasta qué punto tenía competencia como conferencia diplomática internacional. En su calidad de conferencia sólo puede actuar en ejercicio de las competencias retenidas por los Estados y no atribuidas a la UE.

Al haber sido adoptada en la ambigua naturaleza de «poder constituyente» o conferencia internacional que adopta acuerdos políticos, pero al mismo tiempo son miembros del Consejo Europeo, se deben al respeto del Derecho originario o Tratados por lo que no pueden menos de mostrar formalmente su intención de no modificarlos hasta una reforma formal. No tienen competencia para modificar los Tratados constitutivos por sí solos, ni como institución, ni como conferencia internacional o poder constituyente.

La Decisión atípica del Consejo Europeo era un acuerdo regido por el Derecho internacional que hacía una promesa ad futurum: se concertaban para cambiar algunas normas en el futuro conforme al procedimiento de revisión (anticipan el contenido de una futura reforma formal y legal que más tarde tomará la forma y procedimiento del art. 48 TUE) y se anunciaban limitadas reformas en Derecho derivado con el compromiso del Consejo de hacer todo lo necesario por su parte, si bien hubiera dependido

han aceptado que sus relaciones mutuas, en lo que atañe a las materias que han sido objeto de un traspaso de competencias de los Estados miembros a la Unión, se rijan por el Derecho de la Unión, con exclusión, si así lo exige éste, de cualquier otro Derecho». También la Sentencia núm. C-28/12, de 28 de abril de 2015, Comisión v. Consejo, ap. 44, confirma antigua jurisprudencia referente a que «las normas relativas a la formación de la voluntad de las instituciones de la Unión están establecidas en los Tratados y, por tanto, no tienen carácter dispositivo ni para los Estados miembros ni para las propias instituciones») (Sentencias núm. 68/86, Reino Unido v. Consejo, y núm. C-133/06, Parlamento v. Consejo).

${ }_{17}$ Así lo califica el Informe del Servicio Jurídico EUCO 15/16 (JUR, 64, de 8 de febrero de 2016).

El Reino Unido notificó oficialmente al secretario general de Naciones Unidas la conclusión del acuerdo a los efectos del art. 102 de la Carta (invocación ante los órganos de la ONU) el 25 de febrero de 2016 (bttp://uk.reuters.com/article/uk-britain-eu-un-idUKKCNOVX2VO). 
del acuerdo del Parlamento Europeo para algunas reformas legislativas. Decían que no modificaban los Tratados, pero contenían varios compromisos acordados de incorporar los contenidos de los acuerdos a los Tratados en reformas futuras.

Otro aspecto relevante del rol asumido en la Decisión era el de intérpretes de los Tratados y del Derecho derivado existentes. Los Estados pueden hacer declaraciones interpretativas en relación con un tratado del que son partes ${ }^{18}$. Los Tratados de la UE tienen diversas declaraciones interpretativas conjuntas o por separado, pero el intérprete auténtico y definitivo que tiene asignada la función en los Tratados es el Tribunal de Justicia (art. 19 TUE); sólo esta institución tiene la última palabra y no los jefes de Estado.

La Decisión enfatizaba de forma preocupante que era «totalmente» compatible con los Tratados y que no alteraba los poderes de las instituciones ni los procedimientos legislativos. Los jefes de Estado o de gobierno pretendieron erigirse en legibus solutus. La Unión es una unión de Derecho y no cabe legislador sin ataduras, no cabe el poder absoluto.

No era la primera vez que una UE tan heterogénea reconocía jurídicamente estatutos especiales y diversos entre sí. Además del Reino Unido, Dinamarca, Irlanda, Polonia, República Checa y Suecia tienen regímenes particulares. La Unión Europea ha sido flexible y admitido diversos estatutos a la carta, pero siempre ha sido con un consenso cruzado y no asimétrico como en la Decisión non nata. Y cuando ha admitido estatutos diferenciados o asimétricos se ha hecho con todas las garantías procedimentales y democráticas europeas y nacionales: siguiendo las fases de una revisión, incluida la aprobación mayoritaria por el Parlamento Europeo y la de los Parlamentos nacionales por unanimidad. Todos han tenido la misma oportunidad de influir y no es resultado de un diktat. Es cierto que, salvo la exoneración de la cláusula de «una unión cada vez más estrecha», el régimen reconocido no hubiera sido exclusivo del Reino Unido y todos hubieran podido acogerse al régimen pactado. Hubiera sido un preacuerdo sobre una futura reforma de los Tratados.

Ciertamente, el Consejo tenía una difícil salida y el órdago británico iba en serio, como los resultados del referéndum de 23 de junio de 2016 han demostrado.

La Decisión del Consejo Europeo sólo hubiera entrado en vigor tras un referéndum positivo a la permanencia en la UE. Era una oferta política.

${ }_{18}$ Art. 31.3 del Convenio de Viena sobre el Derecho de los Tratados. Sentencia del TJUE núm. C-135/08, de 2 de marzo de 2010, Rottmann, ap. 40. 


\section{EL REFERÉNDUM Y EL DERECHO DE RETIRADA}

Va de suyo que sólo los ciudadanos británicos tenían derecho a participar en la votación y en modo alguno los ciudadanos europeos residentes. La única normativa aplicable era la nacional. Los referendos no son competencia de la UE ni un derecho de la ciudadanía europea. A su vez, la decisión tomada por el pueblo británico será definitiva una vez notificada por el gobierno. Las circunstancias nada tienen que ver con otros referendos como los de Dinamarca (1992-1993) e Irlanda (2002), ligados a la ratificación o no de un tratado de reforma. Aquí ya no habrá posibilidad de otra renegociación y de convocar una nueva consulta sin previas elecciones generales ${ }^{19}$.

$\mathrm{Ni}$ que decir tiene que la retirada de un Estado miembro de la UE es un derecho inherente a la membresía en cualquier organización internacional. Está en el Convenio de Viena sobre el Derecho de los Tratados (art. 56), y la reforma de Lisboa regula en el art. 50 el procedimiento a seguir en caso de notificar la retirada. En todo caso, habría un plazo de dos años para negociar las condiciones de la retirada desde la notificación oficial de retirada y, si no hubiera acuerdo, ello no sería obstáculo para materializar la retirada en ese plazo.

\section{EL TRIUNFO DE LA RETIRADA. CONSECUENCIAS}

$\mathrm{El}$ «no» a la permanencia aboca al Reino Unido a escenarios inquietantes en su política interna y externa.

El gobierno británico, tras el referéndum, deberá someter la decisión final al Parlamento británico y notificar oficialmente la retirada. Esa fecha es determinante para la apertura del plazo de dos años o preaviso para lle-

${ }_{19}$ El Tesoro británico calcula que le costará a cada familia 4.300 libras al año hasta el 2030 (https://www.gov.uk/government/news/eu-referendum-treasury-analysis-key-facts). Vid. el discurso de Cameron en https://www.gov.uk/government/speeches/pm-speech-on-the -uks-strength-and-security-in-the-eu-9-may-2016, y el informe de la Cámara de los Comunes en http://researchbriefings.parliament.uk/ResearchBriefing/Summary/CBP-7213\#fullreport. Es una lástima que estos concienzudos y objetivos análisis no los hicieran en 2013. Políticos irresponsables. Otros informes igualmente pesimistas sobre los efectos económicos del Centre for European Reform en http://www.cer.org.uk/publications/archive/report/2016/ economic-consequences-leaving-eu-final-report-cer-commission-brexit; del FMI en bttp:// www.imf.org/external/np/ms/2016/051316.htm, y de la OCDE en http://www.oecd.org/economy/the-economic-consequences-of-brexit-a-taxing-decision. btm. 
var a cabo las negociaciones sobre las condiciones de la retirada —cómo se irán dejando de aplicar las normas de la UE y, por tanto, el fin del régimen de los derechos y obligaciones del Reino Unido y de la relación integrada con los miembros de la UE_- En ese tiempo se tratará de negociar en paralelo el eventual acuerdo que regule las relaciones posretirada (comerciales y de trato a los nacionales respectivos). En caso de no haber uno u otro acuerdo, o ninguno de los dos, no es óbice para que surta efecto la retirada al cumplirse los dos años de la notificación oficial. También si los veintisiete están de acuerdo — aunque poco probable_ - podría acordarse una prórroga del plazo de negociación; la negociación podría terminar antes del plazo. El Reino Unido tendrá que darse prisa, ser flexible y receptivo. La posición fuerte estará en manos de la UE y sus Estados miembros.

Son interesantes y muy importantes las cuestiones fundamentalmente técnicas y jurídicas que tendrán que ser abordadas para reordenar unas relaciones complejas y extensas que han unido al Estado, empresas y ciudadanía británicas durante más de cuarenta años con el conjunto de la UE. Destejer esa relación requiere sensibilidad y coherencia en los dos años de negociaciones, tras la notificación oficial de la retirada, para establecer las condiciones del divorcio y el marco de la nueva relación. No hay divorcio sin costes.

Hay que poner de relieve la ausencia en el seno de las instituciones de informes sobre las consecuencias exteriores y de seguridad al Brexit ${ }^{20}$. Claro que la excesiva neutralidad y alejamiento del debate ha podido ser perjudicial al dejar todo el espacio y la estrategia a los partidarios del «leave».

${ }^{20}$ Las instituciones — como la Comisión o el Consejo, pero también el Parlamentooptaron por la extrema prudencia. En buena medida se comprendió esa actitud para evitar, desde las islas, el reproche de intromisión en una decisión reservada a la población británica.

Ahora bien, la política del «avestruz» institucional no siempre es la más eficaz; el pluralismo del Parlamento Europeo debió ser un marco adecuado para llegar a la ciudadanía británica. Tampoco la Comisión debió esconderse ni renunciar a «la promoción del interés general de la Unión» (art. 17 TUE), pues el suministro de información objetiva acerca de la Unión Europea y su funcionamiento es parte de esta tarea. Después se ha arrepentido de no haber dado ciertas explicaciones sobre el funcionamiento democrático de la Unión.

La Comisión decidió crear un grupo de trabajo para cuestiones estratégicas relacionadas con el referéndum con el límite de no interferir en un proceso democrático interno. La Comisión consideraba que la UE es más fuerte con el Reino Unido como miembro y el Reino Unido es más fuerte como miembro de la UE, y que esa decisión tendría una importancia estratégica para la Unión en su conjunto (vid. respuestas de la Comisión a preguntas parlamentarias núm. P-013959/2015, de 9 de diciembre de 2015, y núm. E-010888/2015, de 4 de septiembre de 2015, y J.-Cl. JunCKER, «State of the Union 2015. Time for Honesty, Unity, Solidarity», EUISS Yearbook of European Security 2016, p. 136, disponible en bttp:// www.iss.europa.eu/publications/detail/article/euiss-yearbook-of-european-security-2016/. 


\section{La falta de alternativas a la membresía europea}

Se han hecho muchos análisis ${ }^{21}$ sobre las alternativas que tiene el Reino Unido para reordenar su relación con la Unión y ninguna es cré́ble ni comparable con la actual: 1) Negociar un acuerdo de retirada con una relación privilegiada o no. 2) Integrarse en el Espacio Económico Europeo. Pensar en un estatuto como el de Noruega o Liechtenstein es decepcionante para una gran potencia que tendría que aceptar miles de normas sin poder participar en los procesos normativos y políticos. Una humillación a la soberanía británica, aunque se libre de pagar a la burocracia europea. 3) Integrarse en la EFTA (regreso a 1960 con los cuatro que quedan, una mera unión aduanera con Noruega, Suiza, Islandia y Liechtenstein). 4) Modelo suizo con cientos de acuerdos sin acceso a los servicios y la City cortocircuitada. 5) Negociar un acuerdo de libre comercio con la UE —la opción más previsible- . 6) Negociar una Unión Aduanera (como Turquía...) sin acceso al mercado interior. 7) Limitar sus relaciones a las reglas de la OMC (el trato dado a Rusia, China...).

La Commonwealth le sirve al Reino Unido para ganar votaciones de nombramientos en la Asamblea General de Naciones Unidas y en otras organizaciones internacionales, pero no para ser influyente en el mundo o garantizarse exclusivas comerciales.

\section{Algunos problemas intracomunitarios. Gibraltar}

Internamente tendría que afrontar que Escocia es abiertamente europeísta y el fantasma del independentismo se agudizaría. Los acuerdos del «Viernes Santo» (1998) para Irlanda del Norte tienen como referencia de fondo la común pertenencia de Irlanda y del Reino Unido a la UE, proce-

${ }^{21}$ J.-Cl. PIRIS, «Brexit or Britin: Is it really Colder Outside?», European issues, núm. 369, Fundación Robert Schuman, 2015, disponible en bttp://www.robert-schuman.eu/ en/doc/questions-d-europelqe-355-bis-en.pdf; del mismo autor, entre varios trabajos casi coincidentes, «If the UK Votes to Leave», Centre for European Reform, disponible en $b t t p: / /$ www.cer.org.uk/publications/archive/policy-brief/2016/if-uk-votes-leave-seven-alternatives-umembership, y J.-P. JACQUÉ, «Un enjeu externe ou interne pour le Royaume Unie?», Revue Trimmestrielle de Droit Européen, núm. 4 (octubre-diciembre de 2015), pp. 683-688.

Vid. igualmente la clarificadora información del gobierno británico en su informe sobre The Process for Withdrawing from the European Union, disponible en bttps://www.gov.uk/ government/publications/the-process-for-withdrawing-from-the-european-union. 
so que se podría ver interrumpido si sale el Reino Unido de la UE originando la reapertura de los controles fronterizos de personas y mercancías entre Irlanda y el Ulster, y las consiguientes tensiones ${ }^{22}$. A su vez, Francia dejaría de asumir en Calais el sucio papel de frenar en el continente mismo la llegada de inmigración ilegal al Reino Unido.

La retirada británica tendría consecuencias para Gibraltar, la colonia británica en España. Los tratados internacionales no son compartimentos estancos y tienen efectos sobre tratados anteriores o posteriores (art. 30 del Convenio de Viena sobre el Derecho de los Tratados): el Tratado de Utrecht permitía el cierre de la comunicación terrestre entre Gibraltar y el territorio español circunvecino con plena discrecionalidad por parte de España $^{23}$. Desde la adhesión en 1986 a los Tratados comunitarios, España perdió aquella facultad por el efecto de un tratado posterior entre los dos Estados que obligaba a permitir la libre circulación de personas, servicios y capitales.

Desde entonces España ha estado obligada por la normativa europea a garantizar la apertura constante de la comunicación terrestre y la consiguiente libre circulación, residencia y derecho a trabajar de los nacionales de los Estados miembros. Si bien, como el Reino Unido tiene una excepción en el código de fronteras Schengen - mantiene los controles fronterizos-, España está facultada a hacer controles a personas y vehículos a su entrada o salida por la verja. Además, como Gibraltar está excluido de la Unión Aduanera y de la armonización fiscal, ha estado plenamente justificado el control de las mercancías, pues eran equivalentes a mercancías de terceros países. En todo caso, los controles de personas y mercancías debían hacerse con la debida proporcionalidad sin tener el efecto de impedir el paso de las personas.

Al consumarse la retirada del Reino Unido tras la negociación, o en todo caso a los dos años de la notificación oficial, se dejarán de aplicar

${ }^{22}$ Vid. Britain and Europe: The Endgame. An Irish Perspective, Dublin, IIEA, 2015, y Britain and Europe: the Endgame. A Post-script, Dublin, 2016, disponible en en bttp://www. iiea.com/publications.

${ }^{23} \mathrm{El}$ art. X del Tratado de Utrecht establece el cierre de la comunicación terrestre como la opción exigida por España. Sin embargo, salvo en los años iniciales, hubo siempre una gran porosidad y el cierre de la puerta de la muralla no era tan habitual, y se demuestra con la ocupación lenta de dos tercios del istmo y la construcción de una verja por Gran Bretaña en 1908, estabilizando el territorio usurpado. El periodo mayor de cierre de la comunicación terrestre fue durante la dictadura del general Franco en 1969, prolongado en la transición democrática hasta 1982 (apertura peatonal) y definitiva y plenamente abierto el paso por la verja a todo tipo de tráfico desde el 7 de febrero de 1985 . 
los Tratados de la UE y, a reserva de lo que se pacte entre los veintisiete y el Reino Unido para su salida ordenada y la futura relación con la UE, se restablecerían las plenas facultades soberanas de España. Aquí se vuelve al punto de partida, es decir, el Tratado de Utrecht, pudiendo impedir el paso de personas, servicios y mercancías a discreción. Ya he señalado que habitualmente ha estado abierto al paso de personas, vehículos y mercancías, por lo que no habrá cierre, pero España recobra, sin inspecciones de la Comisión Europea, la plena facultad de hacer controles tan rigurosos como crea oportunos y convenientes, y, llegado el caso, cerrar el paso cuando lo estime necesario o denegar la entrada de gibraltareños concretos conforme a las normas para las fronteras exteriores.

Igualmente decidirá libremente sobre las condiciones futuras (nuevas solicitudes) para la residencia y el acceso a trabajos y servicios de personas de origen gibraltareño o excluirles para el futuro, como del conjunto de ciudadanos británicos en España - y a la vista del previsible acuerdo de relación con el Reino Unido-. En todo caso, aunque habrá efectos negativos para los gibraltareños, todos sabemos la importancia de Gibraltar para el empleo en el Campo de Gibraltar.

Sin embargo, en cuanto a las propiedades, negocios y derechos adquiridos por los gibraltareños en España al amparo de la aplicación de las normas de la UE hasta la terminación de la membresía británica, no se verán afectados por la retirada de la UE aunque su régimen será interno. En efecto, los derechos, obligaciones o situaciones jurídicas creadas por la ejecución de un Tratado durante su vigencia deberán ser respetados [art. 70.1.b) del Convenio de Viena citado y de conformidad con el principio de respeto a los derechos adquiridos]. De nuevo, a reserva de lo que se negocie con el Reino Unido para la relación futura, España debería defender encarecidamente sus intereses y no hacer concesiones graciosas sin compensaciones adecuadas (por ejemplo, poniendo límites a la trasmisión futura - inter vivos y mortis causa- de las propiedades y negocios de personas y sociedades gibraltareñas localizadas en España).

También Gibraltar dejará de estar sujeto a la normativa de la UE en materia de sociedades — que apenas cumple - o a la normativa medioambiental, entre otras, y a los controles, advertencias y presiones de la Comisión Europea. Tampoco España tendrá que rendir cuentas a la Comisión.

Ahora bien, la múltiple controversia se abrirá en todos sus frentes: colonial (territorios cedidos), territorial (istmo usurpado), marítimo y aéreo. Despertaremos todos de la anestesia que sobre los conflictos territoriales produce la común pertenencia a una organización de integración. 
Compartir un espacio jurídico, económico y social integrado ayuda a sublimar los conflictos territoriales.

$\mathrm{Al}$ margen de la gran controversia sobre Gibraltar, hay que reconocer que con la retirada del Reino Unido la Unión perderá a un buen Estado de Derecho, a un buen socio cumplidor. Sí. Lo discute todo, pero cuando se aprueban las normas las cumple. El Reino Unido parecía el menos europeísta de todos los Estados miembros, pero es muy cumplidor. En 2014 el Reino Unido era el noveno mejor en el informe anual de la Comisión sobre el respeto al Derecho de la UE, mientras que España ocupaba la posición vigésimo sexta de veintiocho Estados. En 2014 España tenía ocho sentencias condenatorias sin ejecutar y el Reino Unido ninguna. Entre 1986 y 2015 a España se le demandó con 244 recursos por incumplimiento en treinta años; por el contrario, sólo 139 al Reino Unido en sus cuarenta y tres años en la UE (1973-2015). España se mira cada mañana al espejo y se pregunta - como la madrastra de La Cenicienta - si hay algún otro Estado más europeísta que nosotros. En fin, los españoles somos devotos europeístas, pero pecadores; los británicos son agnósticos, pero legales.

\section{RETIRADA Y RELACIONES EXTERIORES}

\section{No hay restitutio in integrum}

No hay retorno al pasado. Después de cuarenta y tres años de unión, incluso sin amor y sólo de conveniencia exitosa, no se vuelve al punto de partida. El Reino Unido no podrá volver al punto en que dejó sus relaciones exteriores en 1972. Y no sólo porque su entorno y el mundo han cambiado profundamente, también el propio Reino Unido. No puede volver de forma instantánea a las relaciones comerciales, económicas, pesqueras o de seguridad y defensa existentes con los Estados terceros. Todos los actores, intereses, riesgos, amenazas, tensiones y conflictos son distintos.

\section{Reconstruir su propia red de acuerdos con terceros}

Las relaciones exteriores son cuantitativa y cualitativamente comerciales y económicas. Lo principal es que aquellas relaciones que tenía el Reino Unido en 1972 ya no existen y tendrá que reconstruir otras distintas. Un efecto claro del triunfo del Brexit es la necesidad imperiosa para el Reino 
Unido de reconstruir toda la red de acuerdos comerciales y económicos (incluidos los de inversiones, los pesqueros, etc.) que tiene tendidos la UE con el conjunto de países y grupos de Estados y organizaciones internacionales. Desde el triunfo de la retirada debe comenzar a hacerlo con rapidez para poder sustituir la maraña de acuerdos que le permitan conectarse con el comercio y la economía internacional y seguir comerciando con terceros Estados (a ser posible antes de los dos años de plazo máximo para negociar en paralelo sus relaciones comerciales y demás con la propia UE). El propio gobierno británico reconoce (en el informe citado en la nota 21) que esto llevará bastantes años y no hay garantía de que el Reino Unido negocie condiciones tan buenas como las que disfruta la UE.

Incluirá ese esfuerzo negociador el examen de los compromisos internacionales en materia medioambiental que tiene concluidos la UE y tendrá que asumir el desarrollo normativo interno de los convenios internacionales concluidos en el marco de las Naciones Unidas y de otras conferencias y organizaciones internacionales que hasta ahora ejecutaba normativamente la UE.

Todo ello, negociar acuerdos comerciales o pesqueros y desarrollo legislativo interno — como reconocía el gobierno británico-, lo hará desde la inexperiencia de más de cuarenta años sin sostener negociaciones comerciales con terceros Estados y sin la infraestructura técnico-diplomática de la Unión, al ser la política comercial una competencia exclusiva de la UE y desempeñada por la Comisión.

Un aspecto delicado de las relaciones comerciales en tanto que política exterior son las sanciones comerciales, también competencia de la UE. El gobierno y Parlamento británicos tendrían que decidir la implementación de sanciones decididas por el Consejo de Seguridad de Naciones Unidas (por ejemplo, Corea del Norte) y decidir si mantienen en otros casos sanciones cuando la decisión se adoptó por la propia UE (por ejemplo, Rusia). El régimen de sanciones inteligentes a Estados, grupos terroristas e individuos ha requerido un marco jurídico sólido y coherente en la UE, además de un sistema de recursos para preservar los derechos de la defensa y tutela judicial en el marco del Estado de Derecho; todo ello hasta ahora suplido por la UE para los veintiochos Estados.

\section{Impacto sobre la Política Exterior y de Seguridad Común (PESC)}

El posible abandono británico no cambiará tan rápidamente la política exterior de la UE, que probablemente seguirá siendo intergubernamen- 
tal, entre otras razones porque el Reino Unido no camina solo en su deseo de que siga siendo así.

Y no deja de ser irónico que el Reino Unido se retire cuando se ha tenido que sentir más cómodo con las sucesivas ampliaciones de la UE, dado que una amplia mayoría de los nuevos Estados miembros se ha alineado con las percepciones de éste en materia de política exterior ante conflictos con Estados como Rusia y Ucrania. Ya no estará dentro para promover su propia opción y liderar a esos Estados miembros del este y embridar a la UE según sus propios intereses y percepciones.

Es una obviedad que la decisión de abandonar afectará a la reconocida influencia, para bien o para mal, del Reino Unido en materia de Política Exterior y de Seguridad Común (PESC). Influencia tiene, sin duda, aunque no siempre en el sentido positivo y de avance de la PESC. El fuerte apego británico a una política exterior intergubernamental y a acciones limitadas en todo caso, junto a su oposición a una política de seguridad y defensa, han debilitado a Europa como potencia con proyección global.

Poco amigo de estructuras y procedimientos, Londres o bien ha ejercido el bloqueo o bien ha mostrado activismo, por ejemplo, en materia de sanciones comerciales a Rusia, sabiendo el fuerte impacto de un conjunto económico tan importante y de haber protagonizado ese activismo al servicio de la visión e intereses de su propia política exterior. Tampoco ha sido muy distinto a otros Estados miembros que se mueven en la PESC en función de su interés nacional. En ocasiones recientes incluso ha estado ausente de grandes acciones como los Acuerdos de Minsk II, liderados en exclusiva por Alemania y Francia.

Claro que el abandono británico no permite deducir alegremente que se generen oportunidades para la política exterior de la UE, ni menos aún que por fin la UE sea un actor más integrado, coherente y activo en política exterior. La ausencia británica no posibilitará una política exterior y de seguridad propia y de impacto. Será algo menos difícil, quizá funcione algo mejor, quizá, pero las percepciones y sensibilidades siguen siendo variadas y contrapuestas. No habrá automatismos en los beneficios potenciales y una UE sin los británicos perderá credibilidad por su prestigio y capacidad de influencia ante el mundo, así como porque quedará limitada la ambición y el alcance estratégico de la misma. Se verá en esa pérdida una prueba más del declive del continente. En todo caso, la pérdida de confianza interna y externa por la retirada puede llevarnos a la confusión y la parálisis.

Una conclusión semejante se aplica al Reino Unido: perderá claramente más de lo que cree que ganará en términos de influencia global. Su ingreso 
en la UE le permitió reconducir la crisis de identidad poscolonial y mantener una posición privilegiada ante el mundo.

Se puede comprender que el Reino Unido tenga el sueño de ser un actor individualizado en la sociedad internacional porque su sociedad ha cultivado la conciencia de su pasado y conserva esa voluntad. Su determinación es envidiable, pero el pasado no vuelve ${ }^{24}$. No se recupera. Hoy, si el Reino Unido es considerado una potencia influyente en el mundo, si se le considera potencia, es por ser miembro de la UE y por ejercer influencia (y control) dentro de la UE en materia de política exterior. La aspiración de que el Reino Unido sea una nación independiente sin ataduras y un actor relevante en el ámbito internacional no es creíble debido a la cambiante realidad internacional en la que los Estados sólo controlan una parte del poder y, también, a que los problemas globales son desequilibrantes — desde el cambio climático a los Estados fracasados y el terrorismo yihadista; además de los recortes acumulados en el pasado al presupuesto británico en defensa y política exterior- ${ }^{25}$.

La retirada les librará de algunas desventajas de operar a través de la UE como son las dificultades europeas para la formulación de una estrategia exterior fuerte y clara; del liderazgo desigual — dos Estados con determinación frente a la atonía, con matices, de veintiséis Estados-; de la complejidad institucional que puede impedir la aplicación de la política, y las sensibilidades e intereses diferentes. La ausencia definitiva del Reino Unido de la toma de decisiones en política exterior dejará en soledad estratégica a Francia. Pero también tendrá el Reino Unido que renunciar a que la UE refleje los intereses y prioridades británicos. Por tanto, la retirada tendrá importantes consecuencias negativas para los intereses de la política exterior del Reino Unido y también para la UE.

La pertenencia del Reino Unido a la UE forma parte de su soft power. También puede decirse en sentido inverso, la presencia y fuerza disuasoria británica es parte considerable del soft power europeo. La interacción es mutua: se beneficia y nos beneficia por ser una economía saneada, un Estado con inmejorables relaciones exteriores y el de mayor influencia internacional de la UE. No poder contar con su prestigio internacional

${ }^{24}$ El espléndido aislamiento que añoran los partidarios del Brexit es una alucinación nostálgica. Es bien sabido que fue un mito, una quimera, ni hubo aislamiento, ni fue tan espléndido.

${ }_{25}$ Si bien el Reino Unido es el Estado miembro que más gasta en defensa, seguido por Francia y Alemania. En 2015 descendió el gasto militar en 0,4 por 100; desde 2017 ha bajado el 14,5 por 100 en términos reales en el conjunto de la UE (Yearbook..., op. cit., p. 90). 
nos debilitará extraordinariamente, en especial cuando los intereses económicos y geoestratégicos se desplazan a Asia. Aunque tiene una visión individual más proclive a proteger los intereses estratégicos de Estados Unidos, las aportaciones del Reino Unido en la concepción de la PESC, capacidad de análisis, planificación y propuesta son imprescindibles, así como su determinación en la decisión y sus aportaciones en la ejecución de la PESC y de la PSCD.

Otro elemento de reflexión para el Reino Unido deberá ser el debilitamiento y, en parte, la obsolescencia de las organizaciones internacionales derivadas de la Segunda Guerra Mundial. La reforma y adaptación a los nuevos tiempos del sistema institucional internacional o la creación de nuevos instrumentos estables de cooperación para ser eficaces sólo podrá hacerse desde una UE pujante y responsable. Influir para la renovación del sistema internacional deberá ser un motivo de implicación europea del Reino Unido.

\section{La relación con Estados Unidos}

Con su retirada, el Reino Unido perderá su capacidad de influencia en la UE. Éste ha sido el tradicional interlocutor de Estados Unidos dentro de la UE, su caballo de Troya. Ese papel le ha hecho especialmente valioso para Estados Unidos y le permitía una relación más equilibrada con la superpotencia. Con el Reino Unido dentro, Estados Unidos puede influir en la UE; fuera de la Unión, a Estados Unidos le vale poco; pasará a ser un socio menor de éstos. Si abandona la UE su valor estará a la baja ante Estados Unidos y ante el mundo.

La pérdida de relevancia del Reino Unido para Estados Unidos por la retirada era una obviedad para los analistas. No era sin fundamento ese amplio consenso, confirmado por el propio presidente Barack Obama de nuevo en su viaje a Europa en la primavera de 2016 y otras personalidades como Hillary Clinton, de que la relación especial entre Estados Unidos y Reino Unido se debilitaría tanto en su relación bilateral como multilateral. Tanto es así que, a pesar del temor de que las opiniones de líderes extranjeros puedan interferir, el presidente Obama dejó claro que, aunque la relación especial sea eterna, la permanencia es del interés de Estados Unidos, así como afirma que la UE no reduce el poder del Reino Unido, al contrario, lo magnifica - llegó a decir- Frente a los partidarios de la retirada que especulan con un próximo y buen acuerdo directo comercial entre 
Estados Unidos y el Reino Unido, el presidente Obama lo descartó en un plazo medio ${ }^{26}$, añadiendo que el Reino Unido tendría que esperar su turno. En efecto, confirmó que la prioridad para Estados Unidos es el Acuerdo de Libre Comercio Transatlántico con la UE (TTIP).

Por ello, el deseo e interés de Estados Unidos es que su aliado británico refuerce su peso e influencia en la UE no sólo para que gane el libre comercio, sino también, obviamente, la seguridad.

Claro que, visto desde la perspectiva de los detractores del acuerdo transatlántico de comercio e inversiones, la retirada británica será una agradable noticia, pues se pierde al socio europeo más interesado en la desregulación normativa de la economía europea. La posición más favorable a la contraparte norteamericana se esfumará frenando el acuerdo o cambiándolo significativamente.

$\mathrm{Y}$ sin olvidar que en los últimos meses se viene notando una especial fluidez en la relación de Estados Unidos con Alemania, tanto en materia financiera y comercial como de seguridad (Rusia, Ucrania...). Ante las dudas e inhibiciones británicas también se observa cierta cooperación con Francia en el norte de África y Sahel, lo que podrá facilitar el tránsito hacia el eje franco-alemán para obviar el vacío que dejaría el Brexit.

\section{SEGURIDAD Y DEFENSA}

Si hablamos de la Política Común de Seguridad y Defensa (en adelante PCSD), ¿se verá irremediablemente afectada?

Sin el Reino Unido en la Unión habrá menos oposición a la PCSD y a la futura política de defensa propia europea. El Reino Unido tiene un veto permanente sobre el desarrollo de la PCSD y se ha asegurado de forma consistente que sea compatible con la OTAN. En caso de abandonar la UE perderá esa influencia y sus temores podrán convertirse en una realidad.

Sin el Reino Unido se perderán las mejores capacidades militares disponibles de una gran potencia militar, incluso a pesar de que los importantes recortes presupuestarios desde la crisis financiera hayan disminuido el poder militar de este país. Este poder viene acompañado de una cultura estratégica; es un Estado con determinación, con la influencia decisiva

${ }^{26}$ Confirmando la posición del representante norteamericano de Comercio Exterior, Michael Froman: «EEUU no está en el mercado para acuerdos de libre comercio con países individuales» (El País, 22 de abril de 2016). 
en el seno de la OTAN y que sabe combinar esos activos junto a su experimentada red diplomática para transformarlos en influencia global. En efecto, hay mucho en juego para la UE en el Brexit, pues perderá una potencia nuclear y un miembro del Consejo de Seguridad de la ONU y, sobre todo, uno de los dos ejércitos de Estados miembros con capacidad significativa de despliegue en el exterior. Incluso con un Reino Unido menos influyente por su retirada y con una debilidad significativa de la UE en el largo plazo, las inescrutables opciones de cara a una futura defensa común quedarán seriamente dañadas por la privación de las capacidades militares.

Pero no nos abandonemos a una visión catastrofista. No habrá un impacto negativo arrollador.

En primer lugar, porque los diversos gobiernos británicos apenas se han comprometido hasta ahora con la PCSD por temer que una capacidad militar autónoma europea pudiera hacer sombra a la OTAN, preservando la primacía de esta organización militar y haciendo difícil, imposible o mínima la PCSD. Además, el Reino Unido hace tiempo que no confía en que una mayoría de Estados miembros puedan convertirse algún día en socios militares creíbles. El Reino Unido ha hecho la guerra total a la PCSD movilizando todos sus recursos a fin de impedir la formación de una capacidad propia de la UE para hacer frente a su seguridad y defensa. Por ejemplo, siempre ha vetado cualquier propuesta de un cuartel general militar de la UE por considerarlo una duplicidad y se opuso a aumentar el presupuesto para la Agencia Europea de Defensa, o impidió las cooperaciones estructuradas.

Es claro que el Reino Unido evita la colaboración y profundización en la seguridad y defensa en estructuras nuevas en el seno de la UE. En parte debido a que es uno de los ámbitos menos avanzados, pues los Estados miembros de la UE siguen siendo reacios a integrar aún más sus instrumentos de seguridad, a pesar de que la crisis debiera haber empujado a «agrupar y compartir» coordinando los ajustes.

En segundo lugar, el hecho de que Estados Unidos esté asumiendo con discontinuidad su rol de superpotencia y se gire cada vez más hacia el Pacífico Sur y exija de Europa una mayor responsabilidad en la seguridad y defensa, seguramente ha inclinado al Reino Unido a estrechar la cooperación militar bilateral con Francia, como revela el Tratado de Cooperación en Defensa firmado en Londres (acuerdos de Lancaster House) en 2010 en el que ambos Estados expresaron su voluntad de ejercer un liderazgo conjunto con acuerdos concretos en materia nuclear y convencional (despliegue conjunto, transferencia de tecnología, programa de compras, etc.). 
Aunque Francia sostiene la necesidad de una capacidad independiente militar de la UE, ello no impide la colaboración franco-británica, que se explica por la denodada decisión británica de evitar pasar por un sistema común europeo ${ }^{27}$. Pero hay que reconocer que ese acuerdo no está pasando por sus mejores momentos y muestra fragilidades en las adquisiciones militares.

A pesar de la oposición británica a una política propia de seguridad y defensa, y de concepciones tan contrapuestas de la integración y del atlantismo, Francia seguramente se sentirá bastante sola si el Reino Unido abandona la UE. Francia se ha entendido bien con el Reino Unido, le ha permitido rebajar el predominio de Alemania en el conjunto de la integración y demuestra que las concepciones contrapuestas pueden cohabitar en la UE, incluso en materias delicadas como la seguridad y la defensa. También es cierto que Francia encuentra en la UE y en la PCSD un multiplicador de su potencia y un medio para asegurar su influencia; lo mismo le sucede al Reino Unido, pero no tiene conciencia de ello.

En tercer lugar, el deterioro de las condiciones de seguridad en 2014 y 2015 ha cambiado el enfoque de la seguridad, y la UE es cada vez más propensa a asumir una parte mayor de la carga de la seguridad global. Es cierto que cuando el premier Cameron lanzó la promesa del referéndum en campaña electoral a principios de 2013 el IS no era una prioridad, la tensión con Rusia no se había manifestado (hasta finales de 2013), no se habían producido las matanzas en París de enero y noviembre de 2015, ni la masiva migración desde Siria (primavera de 2015), ni los acuerdos esperanzadores con Irán (primavera de 2015).

La UE y el mundo occidental han tenido que reordenar sus prioridades en torno a la protección de nuestro modo de vida y las fronteras exteriores. La propia UE está a punto de aprobar su nueva estrategia global de política exterior y de seguridad, y la OTAN abordará la situación en su próxima cumbre (Varsovia, julio de 2016). Todo parece indicar que una retirada no sería una catástrofe per se para la seguridad, pues se tiene conciencia de la trascendental importancia de la necesidad de la cooperación en materia de seguridad y defensa, y de la asunción de responsabilidad bajo control último intergubernamental de su utilización. La retirada conducirá casi inexorablemente a arreglos de seguridad específicos para tender puentes entre el Reino Unido y la UE.

${ }_{27}$ Además, esta política tuvo su origen en una iniciativa franco-británica, la Declaración de St. Malo, firmada por el primer ministro Tony Blair y el presidente Jacques Chirac de Francia en 1998. El Reino Unido ha participado voluntariamente en algunas misiones civiles y militares de la PCSD —en los Balcanes y el cuerno de África—. 
Desde noviembre de 2015 se observa que, desde una perspectiva británica, la cuestión de la permanencia o la retirada se relaciona en última instancia con el papel del país en el mundo y en la seguridad europea. Si la seguridad de Europa era vital para el Reino Unido, ha sido incoherente y frívolo por su parte echar a la suerte de un referéndum su permanencia cuando la eventual salida por accidente podría desestabilizar a la UE.

Ciertamente, la UE y el Reino Unido fuera de la Unión, pero con la conexión atlántica, no podrán inhibirse ni actuar de espaldas al entorno próximo y global; ambos, ya sea unidos, ya sea por separado y asociados, se tienen que implicar en un mundo más conectado, asumir responsabilidad y cooperación - tanto interna como con socios externos- en un mundo más disputado y más complejo. O nos ocupamos del entorno o el entorno se ocupará de nosotros.

Por ello, aun con retirada, habrá cooperación entre el Reino Unido y la seguridad y defensa europea mediante acuerdos específicos, siguiendo y mejorando el modelo de relación con Turquía, aunque renunciando éste a su capacidad actual de influencia sobre esta política. Otra cosa es el juicio que nos merezca la devaluación de la potencia militar y política del Reino Unido, que pudiendo ser el eje de la PCSD pasará a ser a un socio externo como Australia o Nueva Zelanda, aportando capacidades significativas a las operaciones, pero quedando fuera de las decisiones estratégicas clave.

No obstante, sin el Reino Unido, la UE no podrá asumir plenamente los riesgos que corre su seguridad, pero en situaciones que pongan a prueba la paz en Europa el Reino Unido no se podrá desentender de la acción conjunta, ya como socio atlántico, ya como socio externo. Es cierto que los compromisos del Reino Unido, como los del resto de Estados europeos de la OTAN, permanecen en el seno de la organización militar atlántica. No nos confundamos; la Unión Europea ni está preparada ni tiene la voluntad colectiva para conducir acciones coercitivas, que seguirán estando reservadas a la OTAN. El hecho mismo de que la media de los gastos militares de los miembros de la UE sea el 1,28 por 100 en 2014, frente al objetivo del 2 por 100, revela que, con o sin el Reino Unido, la UE no tiene asumida la necesaria solidaridad y responsabilidad, es decir, capacidad real para hacer frente a la seguridad y defensa por sí misma.

La preocupación por la seguridad y defensa es comprensible, pero la confianza y la dependencia mutua facilitarían la cooperación intergubernamental.

En todo caso, la acción militar será necesaria sólo en casos extremos con evaluaciones muy exigentes sobre consecuencias y proporcionalidad, 
habida cuenta las malas experiencias de Irak o Libia, y sabiendo que la superioridad militar por sí sola no es decisiva ante el riesgo máximo que es el colapso de Estados; invasiones desde el exterior y ocupaciones militares han sido derrotas dramáticas en los siglos Xx y XxI. La dominación militar no es eficaz en el medio y largo plazo para los retos de la seguridad nacional y europea como son el terrorismo yihadista infiltrado en nuestras sociedades o los Estados desestructurados y los Estados fallidos.

La ciudadanía de cada uno de los veintiocho Estados miembros exige seguridad, es decir, que organicemos la paz de modo que garantice el respeto a los valores, preservar nuestro modo de ser y de vivir, así como la independencia e integridad de nuestros Estados. Sin seguridad no cabe la prosperidad. Y exige que organicemos la defensa en tiempos de paz a fin de garantizar la realización de esa seguridad. La seguridad y defensa no está garantizada de forma aislada por un Estado, ni siquiera por los mejor dotados militarmente.

Es bien sabido que en el concepto de seguridad contemporáneo los riesgos no son sólo militares ni se pueden examinar aislando nuestros Estados de los análisis referidos a la estabilidad social, económica, política y ecológica de los Estados vecinos. Probablemente, el mayor riesgo para la UE, lo reitero, es el colapso de los Estados en su vecindad (Oriente Medio, Asia, norte de África y Sahel), pues en ellos anidaría un expansivo terrorismo global y multiplicaría las migraciones.

\section{LUCHA CONTRA EL TERRORISMO}

El eje de preocupación internacional será, durante al menos el primer cuarto del siglo XXI, el terrorismo global y la gestión de conflictos armados relacionados con dicho fenómeno (Irak, Afganistán, Libia, Siria, Yemen...). Y su lucha exige coherencia y complementariedad entre la acción interna y externa, y la eficacia de las normas del ELSJ, en concreto optimizar los beneficios de la seguridad de la participación en una serie de medidas de justicia e interior de la $\mathrm{UE}^{28}$.

${ }^{28}$ Desde 2004, la orden de detención y entrega europea ha permitido que varios miles de personas (cerca de 7.000) hayan sido extraditados desde el Reino Unido para ser juzgados en otros Estados miembros y un millar han sido entregados al Reino Unido para responder ante la justicia británica. En concreto, en 2014 las euroórdenes expedidas por Reino Unido fueron 228; las personas arrestadas por el Reino Unido por euroórdenes expedidas por otros Estados miembros fueron 1.519, y las personas efectivamente entregadas por el Reino Unido fueron 1.097. 
Reino Unido perderá la condición de miembro de Europol y de EuroJust, instrumentos que coordinan la lucha contra la delincuencia grave y organizada entre los países de la UE. La cooperación judicial penal, en concreto grandes avances como la orden de detención y entrega europea, y la obligación de reconocimiento mutuo de decisiones judiciales, ya no sería aplicable con el Reino Unido, de modo que habrá que volver a los lentos, complejos e inseguros convenios internacionales de extradición. Se perdería eficacia, mucha eficacia.

La retirada, con un acuerdo paralelo o acuerdos específicos para cubrir estos vacíos, no afectaría al Sistema de Información que permite, si es adecuadamente utilizado, asegurar la información sobre antecedentes penales e información de seguridad relevante, como es el Sistema de Información II, que funciona como una «lista de vigilancia» de acceso a la operativa de datos sobre sospechosos terroristas y criminales. No dudo de la voluntad y el pragmatismo político para evitar un vacío en caso de retirada. Además, resulta irónico que el Reino Unido acabe de aceptar incorporarse, por su propia decisión unilateral al gozar de un opt out desde el Tratado de Lisboa, a la aplicación de las decisiones que comunitarizaron el acuerdo intergubernamental Prüm de 2005 relativo a la información sobre huellas dactilares y $\mathrm{ADN}^{29}$.

En estas materias, la cooperación intergubernamental existente y la que se pueda añadir no creo que provoque vacío en la cooperación británica y europea, al igual que en el alineamiento del Reino Unido con la posición europea en respuestas sociales a los atentados.

\section{CONSECUENCIAS FINALES}

La promesa del referéndum ya ha hecho mucho daño al proceso de integración. Mientras el Consejo Europeo contemplaba absorto como el Reino Unido se miraba su ombligo, los Estados europeos han dedicado más tiempo a los cortafuegos en materia económica o al porcentaje de tarjetas rojas o a los símbolos de la Unión —es decir, a la amenaza británica de retirada- que a las amenazas externas y ataques reales a nuestra seguridad, como el terrorismo internacional o la deficiente cooperación entre policías y servicios europeos de inteligencia. El tiempo gastado en dos

${ }^{29}$ Decisión 2008/61 5/JAI del Consejo, de 23 de junio de 2008, sobre la profundización de la cooperación transfronteriza, en particular en materia de lucha contra el terrorismo y la delincuencia transfronteriza (DO, L 210, de 6 de agosto de 2008). 
Consejos Europeos monográficos sobre el Reino Unido nos ha impedido ocuparnos seria y concienzudamente de la posibilidad de un acuerdo de paz en Siria y de poner fin al flujo de refugiados.

La fiebre referendaria del gobierno conservador ha dañado también la reputación internacional del Reino Unido por la volubilidad de su identidad como Estado (referéndum escocés) y como potencia en el sistema internacional que desconoce las prioridades y responsabilidades de seguridad (referéndum de retirada).

Es cierto que la Unión da muestras de debilidad en su proyecto político, pero no nos engañemos, el proyecto político europeo quedó en entredicho con la macroampliación al este.

Para los europeístas, curtidos en cientos de crisis, la retirada británica debería servir a la Unión para emprender reformas. De momento, calma, reflexionar en torno a lo que se ha hecho mal hasta superar los procesos electorales en Alemania y Francia, y pensar con cabeza qué reformas deben emprenderse, sin tópicos banales de más Europa. La Unión viene dando muestras de debilidad en su proyecto político, en especial desde las ampliaciones del siglo XXI.

El peligro hoy es la desestabilización de Europa por la emergencia de los totalitarismos de derecha e izquierda: el nacionalismo, el proteccionismo, la xenofobia. Ya han triunfado en el Reino Unido. El efecto dominó es previsible y, con ello, el descontrol e inseguridad en toda Europa. ¿Volveremos a 1939, a 1914, al siglo XIX?

Además del shock financiero y económico, éste se puede ver multiplicado por el político, durar más de una década y condicionar este siglo.

Madrid, septiembre de 2016. 